\title{
Balloon-borne resonance fluorescence instrument for in-situ measurement of atomic oxygen: Simultaneous measurement with ozone at 38-44 km
}

\author{
Nobuyuki Takegawa ${ }^{1 *}$, Naomoto Iwagami ${ }^{1}$, and Masahiro Okabayashi ${ }^{2}$ \\ ${ }^{1}$ Department of Earth and Planetary Physics, University of Tokyo, Bunkyo-ku, Tokyo 113-0033, Japan \\ ${ }^{2}$ Department of Geophysics, Faculty of Science, Tohoku University, Aoba-ku, Sendai 980-8578, Japan
}

(Received August 12, 1999; Revised August 1, 2000; Accepted August 8, 2000)

\begin{abstract}
A balloon-borne resonance fluorescence instrument for in-situ measurement of atomic oxygen $\left(\mathrm{O}\left({ }^{3} P\right)\right)$ was developed and its performance was characterized based upon numerical simulations and laboratory tests. A simultaneous measurement of $\mathrm{O}\left({ }^{3} \mathrm{P}\right)$ and ozone $\left(\mathrm{O}_{3}\right)$ in the upper stratosphere was carried out onboard a high altitude balloon launched from Sanriku $\left(39^{\circ} \mathrm{N}, 142^{\circ} \mathrm{E}\right)$, Japan on 9 September $1997 . \mathrm{O}_{3}$ was measured on the same balloon by the solar UV absorption technique. The measured density ratios $\left[\mathrm{O}\left({ }^{3} \mathrm{P}\right)\right] /\left[\mathrm{O}_{3}\right]$ at altitudes $38-44 \mathrm{~km}$ were found to be consistent with the calculated within the experimental uncertainties, although a systematic discrepancy was found above $41 \mathrm{~km}$. It was difficult to make a detailed discussion about this discrepancy due to the insufficient precision and accuracy.
\end{abstract}

\section{Introduction}

In the upper stratosphere and mesosphere, $\mathrm{O}\left({ }^{3} P\right)$ plays an important role in the $\mathrm{O}_{3}$ photochemistry. Because $\mathrm{O}\left({ }^{3} P\right)$ is involved in all major radical catalytic cycles $\left(\mathrm{NO}_{\mathrm{x}}, \mathrm{HO}_{\mathrm{x}}\right.$, and $\mathrm{ClO}_{\mathrm{x}}$ cycles $)$, the accurate determination of $\mathrm{O}\left({ }^{3} \mathrm{P}\right)$ concentration has a strong influence on the calculation of $\mathrm{O}_{3}$ loss rate (Eluszkiewicz and Allen, 1993). Since the photodissociation of $\mathrm{O}_{3}$ and three-body recombination of $\mathrm{O}\left({ }^{3} P\right)$ to form $\mathrm{O}_{3}$ are more than 100 times faster as compared with the reactions including $\mathrm{NO}_{\mathrm{x}}, \mathrm{HO}_{\mathrm{x}}$ and $\mathrm{ClO}_{\mathrm{x}}$ in the upper stratosphere (Jucks et al., 1996; Osterman et al., 1997), the $\mathrm{O}\left({ }^{3} P\right)$ to $\mathrm{O}_{3}$ density ratio is expressed as:

$$
\frac{\left[\mathrm{O}\left({ }^{3} P\right)\right]}{\left[\mathrm{O}_{3}\right]}=\frac{J_{\mathrm{O}_{3}}}{k_{\mathrm{O}+\mathrm{O}_{2}}\left[\mathrm{O}_{2}\right][\mathrm{M}]}
$$

where $J_{\mathrm{O}_{3}}\left(=J_{\mathrm{O}_{3}}\left(\mathrm{O}\left({ }^{1} D\right)\right)+J_{\mathrm{O}_{3}}\left(\mathrm{O}\left({ }^{3} P\right)\right)\right)$ is the photodissociation coefficient of $\mathrm{O}_{3} ; k_{\mathrm{O}+\mathrm{O}_{2}}$ is the reaction rate coefficient of three-body recombination of $\mathrm{O}\left({ }^{3} \mathrm{P}\right)$ and $\mathrm{O}_{2}$. Some investigators recently pointed out that the $k_{\mathrm{O}+\mathrm{O}_{2}}$ value recommended by DeMore et al. (1990) may be underestimated, and this yields overestimate of $\mathrm{O}_{3}$ loss rate in the upper stratosphere (Eluszkiewicz and Allen, 1993; Siskind et al., 1995). This suggests a need for examining the partitioning within the odd oxygen by simultaneous measurements of $\mathrm{O}\left({ }^{3} \mathrm{P}\right)$ and $\mathrm{O}_{3}$ in the atmosphere, as well as better determination of kinetics in the laboratory. However, as far as we know, only a few simultaneous measurements of $\mathrm{O}\left({ }^{3} \mathrm{P}\right)$ and $\mathrm{O}_{3}$ were carried out so far (Anderson, 1975; Anderson et al., 1980), mainly due to the difficulties in the $\mathrm{O}\left({ }^{3} P\right)$ measurement in this region.

*Now at Solar-Terrestrial Environment Laboratory, Nagoya University, Toyokawa, Aichi 442-8507, Japan

Copy right(c) The Society of Geomagnetism and Earth, Planetary and Space Sciences (SGEPSS); The Seismological Society of Japan; The Volcanological Society of Japan; The Geodetic Society of Japan; The Japanese Society for Planetary Sciences.
The VUV resonance fluorescence technique is supposed to be most suitable for measuring $\mathrm{O}\left({ }^{3} P\right)$ in the upper stratosphere; however, it requires us to overcome some technical difficulties such as stable operation of a light source, protection of optics from pollution, reduction of the weight and absolute calibration

In this paper we describe the performances of the resonance fluorescence $\mathrm{O}\left({ }^{3} \mathrm{P}\right)$ instrument and the solar UV absorption $\mathrm{O}_{3}$ instrument, and show the result of simultaneous measurement of $\mathrm{O}\left({ }^{3} \mathrm{P}\right)$ and $\mathrm{O}_{3}$ in the upper stratosphere.

\section{2. $\boldsymbol{O}\left({ }^{3} \boldsymbol{P}\right)$ instrument}

\subsection{Schematic of the instrument}

A balloon-borne resonance fluorescence instrument for insitu measurement of $\mathrm{O}\left({ }^{3} P\right)$ was developed by University of Tokyo and Resonance Ltd. Figure 1 shows a schematic view of the instrument. It consists of an OI resonance lamp with a $\mathrm{MgF}_{2}$ window, a VUV detector and electronics. The OI resonance lamp is an intensive light source of the 130.2, 130.5 and $130.6 \mathrm{~nm}$ triplet lines $\left({ }^{3} S \rightarrow{ }^{3} P\right)$ by utilizing a radio frequency (RF) discharge in a mixture of atomic oxygen and helium gas. The resonance lamp is almost identical with that of Jenkins et al. (1985). The VUV detector is a photomultiplier-tube (PMT) with a CsI photocathode and $\mathrm{MgF}_{2}$ window used in the photon counting mode. The PMT field of view is restricted as shown in Fig. 1 by the light baffles in front of the window. The lamp is modulated turning on and off at 128 $\mathrm{Hz}$ in order to eliminate the background due to the Rayleigh scattering of the solar MUV radiation; the resonance fluorescence count rate is obtained by subtracting the lamp-off signal from the lamp-on signal. The lamp intensity is monitored by detecting OI $777 \mathrm{~nm}$ emission intensity which is approximately proportional to the $130 \mathrm{~nm}$ emission intensity. The optics is protected with an airtight cover against pollutants in the troposphere. The cover is also used as a light 


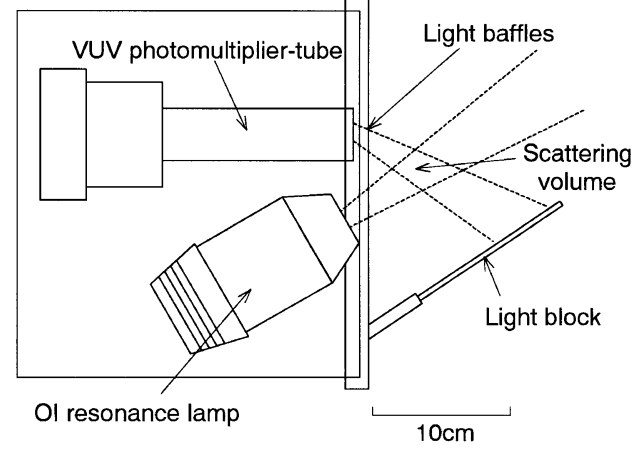

Fig. 1. Schematic view of the $\mathrm{O}\left({ }^{3} P\right)$ instrument. It consists of an OI $130 \mathrm{~nm}$ $\left({ }^{3} S \rightarrow{ }^{3} P\right.$ ) resonance lamp, a VUV detector (PMT), and electronics. The lamp intensity monitor (OI $777 \mathrm{~nm}$ detection optics) is included inside the resonance lamp unit. The PMT field of view is restricted by the light baffles in front of the window.

block when it is open for measurement. The total weight of the instrument is limited to only $6.0 \mathrm{~kg}$ including batteries in order to reach a height of $45 \mathrm{~km}$.

\subsection{Calibration}

In case of the laboratory calibration in a vacuum chamber, the resonance fluorescence count rate detected by PMT is approximated as follows:

$$
\begin{aligned}
& C_{\text {num }} \propto \iiint_{\mathrm{D}} d x d y d z \frac{1}{L^{2}} \frac{1}{L^{\prime 2}} \\
& \times \sum_{J=0}^{2} \int_{\text {line }} d v n_{J}^{\mathrm{O}} \sigma_{J}^{\mathrm{O}}(v) I_{J}(v) \\
& \times \exp \left[-\tau_{J}^{\mathrm{O}}(v)\right] \exp \left[-\tau^{\mathrm{O}_{2}}(v)\right]
\end{aligned}
$$

with

$$
\begin{gathered}
\tau_{J}^{\mathrm{O}}(v)=n_{J}^{\mathrm{O}} \sigma_{J}^{\mathrm{O}}(v)\left(L+L^{\prime}\right) \\
\tau^{\mathrm{O}_{2}}(v)=n^{\mathrm{O}_{2}} \sigma^{\mathrm{O}_{2}}(v)\left(L+L^{\prime}\right)
\end{gathered}
$$

where $J(=0,1,2)$ is the total angular momentum quantum number; $n_{J}^{\mathrm{O}}$ is the number density of $\mathrm{O}\left({ }^{3} P_{J}\right)$ at the scattering point; $\sigma_{J}^{\mathrm{O}}(v)$ is the absorption cross section of $\mathrm{O}\left({ }^{3} P_{J}\right)$; $n^{\mathrm{O}_{2}}$ is the number density of $\mathrm{O}_{2} ; \sigma^{\mathrm{O}_{2}}(v)$ is the absorption cross section of $\mathrm{O}_{2} ; \tau_{J}^{\mathrm{O}}(\nu)$ and $\tau^{\mathrm{O}_{2}}(\nu)$ are the optical thicknesses. $I_{J}(v)(J=0,1,2)$ are the spectral irradiances of the $130.6 \mathrm{~nm}, 130.5 \mathrm{~nm}$ and $130.2 \mathrm{~nm}$ lines, respectively. In accordance with the theoretical model presented by Jenkins et al. (1985), the relative intensities of $I_{J}(v)$ were expressed in terms of double Gaussian spectral line profile with selfabsorption, assuming that $15 \%$ of atomic oxygen in the lamp had the temperature of $5500 \mathrm{~K}$, and $85 \%$ had the temperature of $350 \mathrm{~K}$. The self-absorption effect, the optical thickness in the lamp, was determined based upon the lamp spectrum measured using a high resolution VUV spectrometer. $L$ is the path length from the lamp to the scattering point; $L^{\prime}$ is the path length from the scattering point to the PMT; D is the scattering volume; $v$ is wavenumber.

The instrument was absolutely calibrated at the Institute of Space and Astronautical Science (ISAS). The calibration system and the method were almost the same as for a previous rocket experiment (Kita et al., 1996). Figure 2 shows a schematic view of the calibration system. The instrument

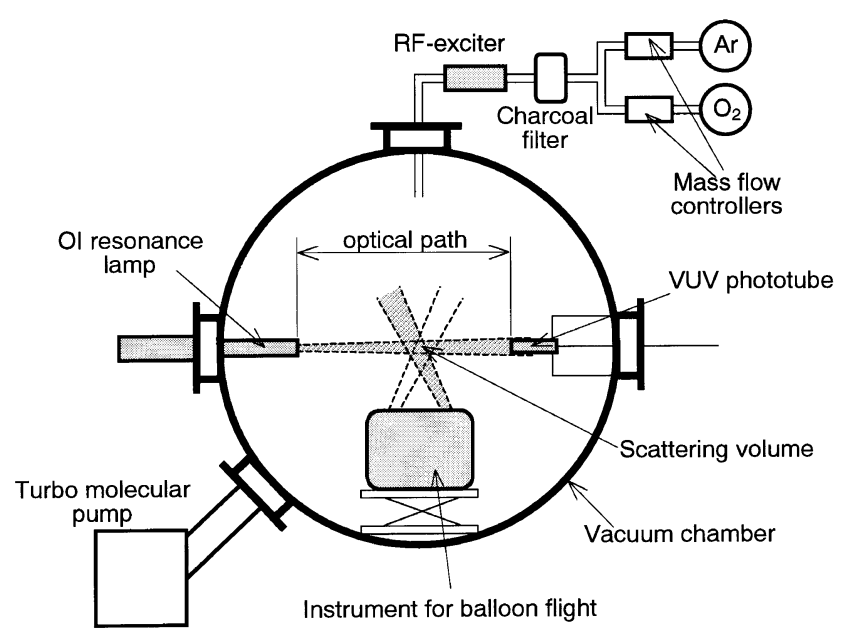

Fig. 2. Schematic view of the calibration system. $\mathrm{O}\left({ }^{3} P\right)$ was generated from mixture of $\mathrm{Ar}$ and $\mathrm{O}_{2}$ gases by RF-discharge and the number density of $\mathrm{O}\left({ }^{3} P\right)$ in the vacuum chamber was monitored by the absorption method using another set of a resonance lamp and a VUV detector.

was set in a vacuum chamber (inner diameter $60 \mathrm{~cm}$, length $100 \mathrm{~cm})$, and $\mathrm{O}\left({ }^{3} P\right)$ was generated from mixture of Ar and $\mathrm{O}_{2}$ gases by RF-discharge. The number density of $\mathrm{O}\left({ }^{3} P\right)$ in the chamber was determined by means of the absorption method using another resonance lamp (calibration lamp) and a VUV phototube. The fluorescence measurements were not affected by the continuous irradiation of the calibration lamp, since the background elimination method was used as described in Section 2.1. The relationship between $\mathrm{O}\left({ }^{3} P\right)$ number density and the VUV phototube output is expressed as follows:

$$
\frac{V_{1}}{V_{0}}=\frac{\sum_{J=0}^{2} \int_{\text {line }} I_{J}(v) \exp \left(-n_{J}^{\mathrm{O}} \sigma_{J}^{\mathrm{O}}(v) l\right) d v}{\sum_{J=0}^{2} \int_{\text {line }} I_{J}(v) d v}
$$

where $V_{1}$ and $V_{0}$ represent the VUV phototube output (excluding the background) with and without atomic oxygen

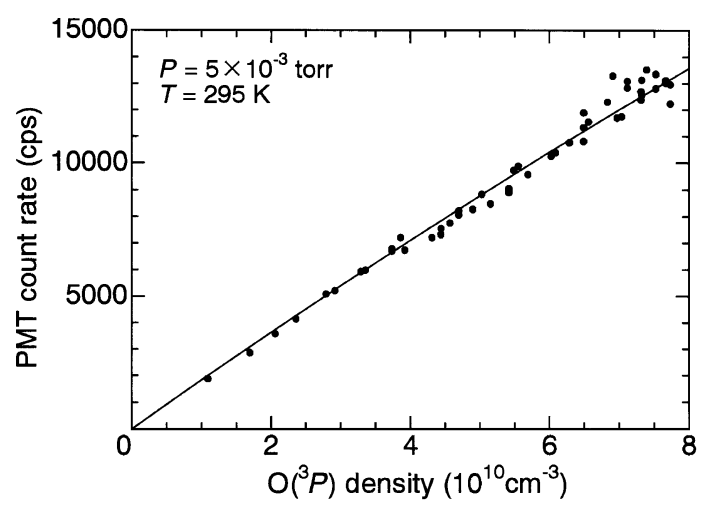

Fig. 3. Calibration results (pressure $5 \times 10^{-3}$ torr, temperature $295 \mathrm{~K}$ ). The instrumental sensitivity factor for a typical $\mathrm{O}\left({ }^{3} P\right)$ number density of $1 \times 10^{9}$ [atoms $\cdot \mathrm{cm}^{-3}$ ] in the upper stratosphere was found to be $(2.0 \pm 0.2) \times 10^{-7}\left[\mathrm{cps} /\left(\right.\right.$ atoms $\left.\left.\cdot \mathrm{cm}^{-3}\right)\right]$. 
generation, respectively; $l$ is the optical path length. The homogeneity of the $\mathrm{O}\left({ }^{3} \mathrm{P}\right)$ density in the optical path was confirmed in the previous experiment (Kita et al., 1996).

Figure 3 represents the calibration result. Random errors for the $\mathrm{O}\left({ }^{3} P\right)$ number density and the PMT count rate were estimated to be about $2 \times 10^{9}$ [atoms $\cdot \mathrm{cm}^{-3}$ ] and $4 \%$, respectively, considering the fluctuations of the observed signals. The curve calculated using Eq. (2) was fitted to the calibration data so as to determine the instrumental sensitivity factor. It is expected to be constant for a typical $\mathrm{O}\left({ }^{3} P\right)$ number density of $1 \times 10^{9}\left[\right.$ atoms $\cdot \mathrm{cm}^{-3}$ ] in the upper stratosphere, and was found to be $(2.0 \pm 0.2) \times 10^{-7}\left[\mathrm{cps} /\left(\right.\right.$ atoms $\left.\left.\cdot \mathrm{cm}^{-3}\right)\right]$. The uncertainty in determining the instrumental sensitivity factor was mainly due to the fitting error and the uncertainty in the oscillator strength of OI $130 \mathrm{~nm}$ resonance line. Although the calibration results were obtained under the conditions of $5 \times 10^{-3}$ torr in pressure and $295 \mathrm{~K}$ in temperature, attenuation of the lamp beam by $\mathrm{O}_{2}$ absorption and the temperature dependence must be considered under the stratospheric conditions. This effect was estimated based upon the numerical simulations described by Eq. (2). Rayleigh scattering of the lamp beam by atmospheric molecules is negligible above 35 $\mathrm{km}$.

\section{3. $\mathrm{O}_{3}$ instrument}

The vertical distribution of $\mathrm{O}_{3}$ is measured by a balloonborne optical sensor (BOS), which was developed by Tohoku University (Okabayashi et al., 1995). This kind of $\mathrm{O}_{3}$ measurement technique was utilized for rocket ozonesondes (Barnes and Simeth, 1986) and the design of BOS is based upon these rocket ozonesondes. As schematically shown in Fig. 4, the BOS optics consists of a diffuser plate, a beam splitter, narrow-band interference filters, quartz lens and silicon photodiodes. The optics has a pair of radiometers: one measures the solar ultraviolet irradiance at $300 \mathrm{~nm}$, while the other measures the solar irradiance at $420 \mathrm{~nm}$ to compensate the variation of solar irradiance due to swaying of the gondola. The full width at half maximum (FWHM) of the 300 $\mathrm{nm}$ narrow-band interference filter is $10 \mathrm{~nm}$, and that of the $420 \mathrm{~nm}$ filter is $15 \mathrm{~nm}$. The process of $\mathrm{O}_{3}$ amount derivation

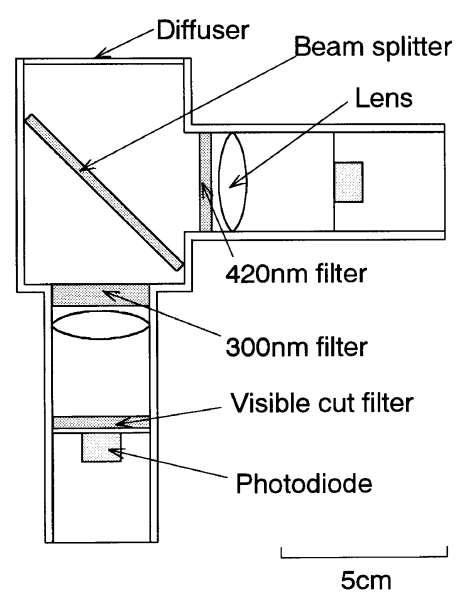

Fig. 4. Schematic diagram of the balloon-borne optical sensor (BOS). The BOS optics consists of a diffuser plate, a beam splitter, narrow-band interference filters, quartz lens and silicon photodiodes. from the measured altitude change of solar ultraviolet radiation was developed based upon the method of Holland et al. (1985).

\section{Balloon experiment \\ 4.1 O $\left({ }^{3} P\right)$ measurement}

The balloon experiment was performed on 9 September 1997 at Sanriku Balloon Center $\left(39.16^{\circ} \mathrm{N}, 141.83^{\circ} \mathrm{E}\right)$ of ISAS using a plastic balloon of $15,000 \mathrm{~m}^{3}$. The balloon was launched at $1050 \mathrm{JST}(0150 \mathrm{UT})$, and the densities of $\mathrm{O}\left({ }^{3} \mathrm{P}\right)$ and $\mathrm{O}_{3}$ were obtained during 1247-1301 JST at altitudes $38-43.6 \mathrm{~km}$ (solar zenith angle was $38^{\circ}$ ) under an ascending speed of $6-7 \mathrm{~m} / \mathrm{s}$. The gondola for the $\mathrm{O}\left({ }^{3} P\right)$ instrument was located $11 \mathrm{~m}$ below the balloon, and the diameter of the balloon was about $33 \mathrm{~m}$ at $40 \mathrm{~km}$. The effect of the balloon on the measurement will be described later. The change in the lamp intensity monitor at $777 \mathrm{~nm}$ was only $+1 \%$ during the measurement.

The total count rate is a sum of the following signals: (a) the fluorescence from $\mathrm{O}\left({ }^{3} P\right)$ in the ambient air; (b) the fluorescence from $\mathrm{O}\left({ }^{3} P\right)$ generated by $\mathrm{O}_{2}$ photodissociation in the lamp beam; (c) Rayleigh scattering of the lamp beam by atmospheric molecules; (d) the elastic scattering of the lamp beam by the light block; (e) the dark count of the PMT. The contribution from (c) was negligible above $35 \mathrm{~km}$ as described before and that from (d) was also negligible according to the laboratory test. The contribution from (b) was estimated to be $47( \pm 24) \%$ of the total signal at $38 \mathrm{~km}$ and $19( \pm 10) \%$ at $43 \mathrm{~km}$, based upon the numerical calculation using the $\mathrm{O}_{2}$ concentration, the lamp photon flux and the air flow rate. The uncertainty in this estimation was mainly due to the uncertainty of the lamp photon flux. The ambient $\mathrm{O}\left({ }^{3} P\right)$ number densities were derived after subtracting (b) and (e) from the total signal.

Figure 5(a) represents the measured $\mathrm{O}\left({ }^{3} P\right)$ number density profile. The data were averaged in the altitude bin of $0.2 \mathrm{~km}$. Error bars added on the profile indicate random errors (one standard deviation). The main cause of the systematic error came from the uncertainty in the calibration and that in the correction (b). The systematic errors at $38 \mathrm{~km}$ and $43 \mathrm{~km}$ were estimated to be $54 \%$ and $22 \%$, respectively, and they are shown in Fig. 5(a).

\section{2 $\mathrm{O}_{3}$ measurement}

Figure 5(b) represents the $\mathrm{O}_{3}$ number density profile measured by BOS. The accuracy and precision in determining the $\mathrm{O}_{3}$ amount mainly depend on the following factors: uncertainty of the absorption cross section of $\mathrm{O}_{3}$; uncertainty of the extraterrestrial solar spectral irradiance; uncertainty of the $\mathrm{O}_{3}$ column amount above the highest altitude attained by the balloon; temperature dependence of the interference filter transmission; random noise and dark signal level of the detector. Taking these uncertainties into consideration, random error and systematic error in the derived ozone number density above $30 \mathrm{~km}$ were estimated to be $6 \%$ and $3 \%$, respectively.

\section{Discussion}

Figure 6 represents a comparison of the measured and the calculated $\left[\mathrm{O}\left({ }^{3} \mathrm{P}\right)\right] /\left[\mathrm{O}_{3}\right]$ ratios. The solid circles indicate 


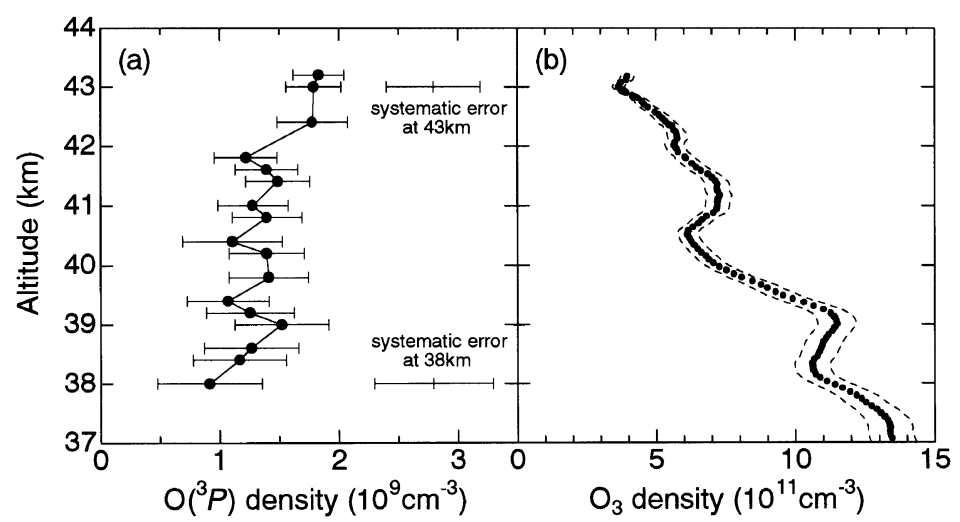

Fig. 5. (a) Altitude profile of $\mathrm{O}\left({ }^{3} P\right)$ measured at $38-44 \mathrm{~km}$ during the balloon ascent. Solar zenith angle was about $38^{\circ}$. Error bars added on the profile indicate random errors (one standard deviation). Systematic errors for the observed values at $38 \mathrm{~km}$ and $43 \mathrm{~km}$ are also shown aside from the plots. (b) Altitude profile of $\mathrm{O}_{3}$ measured during the balloon ascent. Random error and systematic error above $30 \mathrm{~km}$ were estimated to be $6 \%$ and $3 \%$, respectively. The dashed curves enclose the random error range.

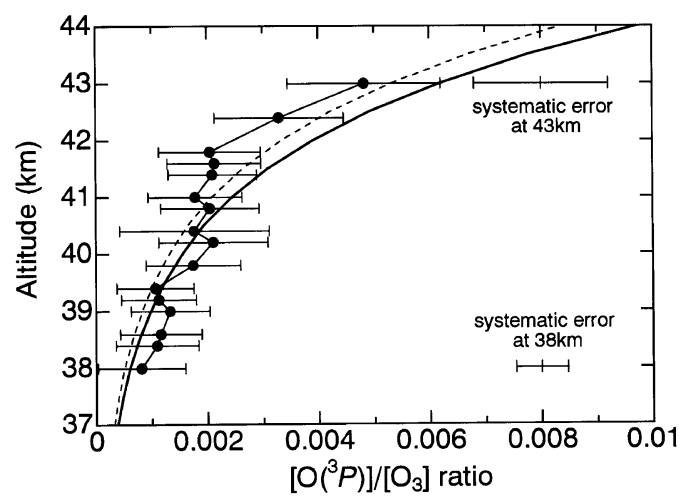

Fig. 6. Comparison of the measured $\left[\mathrm{O}\left({ }^{3} \mathrm{P}\right)\right] /\left[\mathrm{O}_{3}\right]$ ratios with those calculated. The solid circles indicate the measured $\left[\mathrm{O}\left({ }^{3} \mathrm{P}\right)\right] /\left[\mathrm{O}_{3}\right]$ ratios with error bars of two standard deviation. Systematic errors for the observed values at $38 \mathrm{~km}$ and $43 \mathrm{~km}$ are also shown aside from the plots. The thick solid curve indicates the $\left[\mathrm{O}\left({ }^{3} \mathrm{P}\right)\right] /\left[\mathrm{O}_{3}\right]$ ratio calculated using the recommended value of the reaction rate coefficient $k_{\mathrm{O}+\mathrm{O}_{2}}$, and the dashed curve by increasing the reaction rate coefficient within the recommended uncertainty.

the measured $\left[\mathrm{O}\left({ }^{3} \mathrm{P}\right)\right] /\left[\mathrm{O}_{3}\right]$ ratios and the error bars added on the solid circles represent two standard deviation $(95 \%$ confidence limits). Systematic errors for the observed values at $38 \mathrm{~km}$ and $43 \mathrm{~km}$ are also shown aside from the plots. The thick solid curve indicates the $\left[\mathrm{O}\left({ }^{3} \mathrm{P}\right)\right] /\left[\mathrm{O}_{3}\right]$ ratio calculated using Eq. (1) with the recommended value of the reaction rate coefficient (i.e. $k_{\mathrm{O}+\mathrm{O}_{2}}=6.0 \times 10^{-34} \times(T / 300)^{-2.3} \mathrm{~cm}^{6} \cdot \mathrm{s}^{-1}$; DeMore et al., 1997). The dashed curve indicates the $\left[\mathrm{O}\left({ }^{3} \mathrm{P}\right)\right] /\left[\mathrm{O}_{3}\right]$ ratio calculated by increasing the reaction rate coefficient within the recommended uncertainty (i.e. $k_{\mathrm{O}+\mathrm{O}_{2}}=$ $\left.6.5 \times 10^{-34} \times(T / 300)^{-2.8} \mathrm{~cm}^{6} \cdot \mathrm{s}^{-1}\right)$ as suggested by Eluszkiewicz and Allen (1993). Note that $k_{\mathrm{O}+\mathrm{O}_{2}}$ values of DeMore et al. (1990) and DeMore et al. (1997) are identical. The $J_{\mathrm{O}_{3}}$ value was calculated using the solar photon flux, the $\mathrm{O}_{2}$ absorption cross section and the $\mathrm{O}_{3}$ absorption cross section recommended by DeMore et al. (1997). The atmospheric pressures and temperatures used in the calculation of $\left[\mathrm{O}_{2}\right]$ and $[\mathrm{M}]$, and the $\mathrm{O}_{3}$ number densities above the balloon altitude used in the calculation of $J_{\mathrm{O}_{3}}$ were quoted from COSPAR International Reference Atmosphere, 1986 (CIRA1986).

Although the measured $\left[\mathrm{O}\left({ }^{3} \mathrm{P}\right)\right] /\left[\mathrm{O}_{3}\right]$ ratios approximately agreed with the calculated within the experimental uncertainties, they were systematically smaller than the curve of the standard reaction rate coefficient by about $20 \%$ and close to the curve of the increased one above $41 \mathrm{~km}$. However, it is difficult to draw a conclusion that the currently recommended value of the reaction rate coefficient is underestimated; this is not only because the precision and accuracy in this measurement were not sufficient but also because the discrepancy between the measured and the calculated $\left[\mathrm{O}\left({ }^{3} P\right)\right] /\left[\mathrm{O}_{3}\right]$ ratios becomes larger below $41 \mathrm{~km}$ if we adopt the increased reaction rate coefficient.

This discrepancy may come from the measurement. There are three explanations possible. The first explanation is that the ambient $\mathrm{O}\left({ }^{3} P\right)$ was partially destroyed due to the reactions with unsaturated hydrocarbons outgased from the balloon. This effect can explain the discrepancy above $41 \mathrm{~km}$ since the outgas would increase at higher altitudes. The second explanation is the effect of the balloon on the radiation field. Because the balloon was located $11 \mathrm{~m}$ above the gondola for the $\mathrm{O}\left({ }^{3} P\right)$ instrument, it is possible that the solar UV flux in the measurement region was partially cut by the shade of the balloon; this might decrease the $\mathrm{O}\left({ }^{3} P\right)$ production rate. Taking into account the shape of the balloon, the ascent velocity and the lifetime of $\mathrm{O}\left({ }^{3} P\right)$, this shadow effect may explain the discrepancy above $41 \mathrm{~km}$. The third explanation is the decrease of the instrumental sensitivity factor around $41 \mathrm{~km}$ due to the degradation of the lamp window transmission. Although these three explanations have a potential to solve the discrepancy, it is difficult to draw a definitive conclusion since quantitative supports to these explanations were not available.

\section{Summary}

In this paper we described the development of a balloonborne resonance fluorescence instrument for in-situ measurement of $\mathrm{O}\left({ }^{3} P\right)$ and showed the result of simultaneous measurement of $\mathrm{O}\left({ }^{3} P\right)$ and $\mathrm{O}_{3}$. The performance of the $\mathrm{O}\left({ }^{3} P\right)$ instrument was characterized by numerical simulations and 
laboratory tests. Balloon measurement was performed using a high altitude balloon, and the altitude profiles of $\mathrm{O}\left({ }^{3} P\right)$ and $\mathrm{O}_{3}$ were obtained at $38-44 \mathrm{~km}$. The measurement and the calculation were approximately consistent within the experimental uncertainties, although the measured $\left[\mathrm{O}\left({ }^{3} P\right)\right] /\left[\mathrm{O}_{3}\right]$ ratios above $41 \mathrm{~km}$ were systematically smaller than the calculated. However, it was difficult to draw a definitive conclusion that there were some mistakes in our current understanding of the odd oxygen photochemistry, due to the large uncertainties in this measurement.

Acknowledgments. The authors wish to thank W. H. Morrow and K. Kita for their technical support. They also thank to Y. Nakamura, K. Aihara, T. Kawashima, and K. Ito for their assistance during the calibration. The BT15 balloon experiment was carried out under a research program of ISAS. The authors thank T. Yamagami, Y. Matsuzaka, I. Murata, and all the people conducting the balloon experiment.

\section{References}

Anderson, J. G., The absolute concentration of $\mathrm{O}\left({ }^{3} P\right)$ in the earth's stratosphere, Geophys. Res. Lett., 2, 231-234, 1975.

Anderson, J. G., H. J. Grassl, R. E. Shetter, and J. J. Margitan, Stratospheric free chlorine measured by balloon-borne in situ resonance fluorescence, J. Geophys. Res., 85, 2869-2887, 1980.

Barnes, R. A. and P. G. Simeth, Design of a rocket-borne radiometer for stratospheric ozone measurements, Rev. Sci. Instrum., 57, 544-551, 1986.

CIRA1986, COSPAR International Reference Atmosphere, edited by D. Rees, J. J. Burnett, and K. Labitzke, Adv. Space Res., 10(12), 336-339, 1990.

DeMore, W. B., S. P. Sander, D. M. Golden, R. F. Hampson, M. J. Kurylo, C. J. Howard, A. R. Ravishankara, C. E. Kolb, and M. J. Molina, Chemical kinetics and photochemical data for use in stratospheric modeling, Evaluation No.9, JPL Publication 90-1, 1990.
DeMore, W. B., S. P. Sander, D. M. Golden, R. F. Hampson, M. J. Kurylo, C. J. Howard, A. R. Ravishankara, C. E. Kolb, and M. J. Molina, Chemical kinetics and photochemical data for use in stratospheric modeling, Evaluation No.12, JPL Publication 97-4, 1997.

Eluszkiewicz, J. and M. Allen, A global analysis of the ozone deficit in the upper stratosphere and lower mesosphere, J. Geophys. Res., 98, 1069$1082,1993$.

Holland, A. C., R. A. Barnes, and H. S. Lee, Improved rocket ozonesonde (ROCOZ-A). 1: Demonstration of precision, Appl. Opt., 24, 3286-3294, 1985.

Jenkins, D. B., G. Watkin, D. P. Wareing, G. H. C. Freeman, P. H. G. Dickinson, and D. J. Mackinnon, Resolved line profiles of atomic oxygen resonance lamps used in the upper atmosphere, J. Quant. Spectrosc. Radiat. Transfer, 34, 123-132, 1985.

Jucks, K. W., D. G. Johnson, K. V. Chance, W. A. Traub, R. J. Salawitch, and R. A. Stachnik, Ozone production and loss rate measurements in the middle stratosphere, J. Geophys. Res., 101, 28785-28792, 1996.

Kita, K., T. Imamura, N. Iwagami, W. H. Morrow, T. Ogawa, Rocket observation of atomic oxygen and night airglow: Measurement of concentration with an improved resonance fluorescence technique, Ann. Geophysicae, 14, 227-237, 1996.

Okabayashi, M., M. Taguchi, S. Okano, H. Fukunishi, Measurement of stratospheric ozone using a optical ozone sensor onboard a high altitude balloon, Report of the Institute of Space and Astronautical Science, 32, 105-111, 1995 (in Japanese).

Osterman, G. B., R. J. Salawitch, B. Sen, G. C. Toon, R. A. Stachnik, H. M. Pickett, J. J. Margitan, J.-F. Blavier, and D. B. Peterson, Balloon-borne measurements of stratospheric radicals their precursors: Implications for the production and loss of ozone, Geophys. Res. Lett., 24, 1107-1110, 1997.

Siskind, D. E., B. J. Connor, R. S. Eckman, E. E. Remsberg, J. J. Tsou, and A. Parrish, An intercomparison of model ozone deficits in the upper stratosphere and mesosphere from two data sets, J. Geophys. Res., 100, 11191-11201, 1995.

N. Takegawa (e-mail: takegawa@stelab.nagoya-u.ac.jp), N. Iwagami, and M. Okabayashi 